\title{
Prototecose em animais de companhia e aspectos da doença no homem
}

\author{
Protothecosis in companion animals and aspects of the disease in human
}

\author{
Amanda Keller Siqueira ${ }^{I^{*}}$ Márcio Garcia Ribeiro ${ }^{\mathrm{I}}$ Tatiana Salerno ${ }^{\mathrm{I}}$
}

\section{- REVISÃO BIBLIOGRÁFICA -}

\section{RESUMO}

Foram revisados dados de etiologia, epidemiologia, patogenia, sinais clínicos, procedimentos diagnósticos, conduta terapêutica e ações de controle e profilaxia da prototecose em cães e gatos, além de aspectos da doença no homem e em bovinos.

Palavras-chave: Prototheca, prototecose, cão, gato, $\boldsymbol{P}$ zopfii.

\section{ABSTRACT}

Etiology, epidemiology, pathogeny, clinical signs, diagnosis, therapeutic, control and preventive measures in protothecosis in dogs and cats were reviewed, besides aspects of disease in human and bovines.

Key words: Prototheca, protothecosis, dog, cat, P. zopfii.

\section{INTRODUÇÃO}

A prototecose é causada por algas saprófitas e aclorofiladas do gênero Prototheca. Diversos autores postulam que estes microrganismos seriam mutantes das algas verdes do gênero Chlorella (TYLER et al., 1980). O gênero Prototheca tem sido associado a infecções no homem e em animais na Europa, na Ásia, na África, na Austrália, nas Ilhas do Oceano Pacífico e nas Américas (LASS-FLÖRL \& MAYR, 2007). Estes microrganismos são divididos em três espécies principais: Prototheca stagnora,
Prototheca zopfii (P. zopfii) e Prototheca wickerhamii (P. wickerhamii). As duas últimas são reconhecidamente patogênicas para o homem e os animais (RANJAN et al., 2006).

O gênero Prototheca foi primeiramente descrito em 1894 e classificado como alga em 1913(VAN KRUININGEN, 1970). A prototecose canina foi reconhecida como entidade nosológica em 1963 (VAN KRUININGEN et al., 1969). Já o primeiro caso de prototecose felina foi reportado em 1976 (KAPLAN et al., 1976). No Brasil, a prototecose canina foi descrita pela primeira vez por FARIAS et al. (2006), em animal com histórico de colite hemorrágica crônica.

Ao longo dos anos, a prototecose tem sido relatada no homem e em diversas espécies animais, incluindo cães, gatos, bovinos, serpentes, peixes, castores e morcegos (HOLLINGSWORTH, 2000). No Brasil, assim como em outros países, a apresentação clínica mais estudada é a mastite bovina, devido aos prejuízos e à ausência de terapia efetiva.

Recentemente foi proposta a classificação genotípica de $\boldsymbol{P}$. zopfii em três biotipos: I, II e III. O biotipo I predomina nas fezes e no ambiente de criação de bovinos. O biotipo II é encontrado freqüentemente em isolados de mastite bovina e o biotipo III em criatórios de suínos e onicomicose humana (ROESLER et al., 2003). ROESLER et al. (2006) demonstraram com base em técnicas moleculares que $\boldsymbol{P}$. zopfii biotipo III

\footnotetext{
'Departamento de Higiene Veterinária e Saúde Pública, Faculdade de Medicina Veterinária e Zootecnia (FMVZ), Universidade Estadual Paulista (UNESP), Rubião Júnior, s/n, 18618-000, Botucatu, SP, Brasil. E-mail: kellersiqueira@hotmail.com.*Autor para correspondência.
} 
encontra-se filogeneticamente distante dos outros biotipos, propondo nova espécie denominada Prototheca blaschkeae. São escassos os estudos em outros países (TSUJI et al., 2006), tampouco no Brasil, direcionados à caracterização molecular de estirpes do gênero Prototheca isoladas de animais de companhia.

O presente estudo pretende revisar os principais aspectos da prototecose em cães e gatos, além de aspectos da enfermidade no homem e em bovinos.

Etiologia e propriedades gerais

As algas do gênero Prototheca são isoladas em ágar sangue ovino ou bovino (5\%) desfibrinado, em condição de aerobiose. Elas apresentam-se como colônias pequenas, branco-acinzentadas (RIBEIRO et al., 1998; VARGAS et al., 1998; COSTA et al., 2004). No ágar Sabouraud, sem ciclohexamida, formam colônias de tonalidade branca a dourada. De acordo com o meio de cultura empregado, o isolamento do microrganismo pode variar entre dois e sete dias, em intervalos de temperatura de $25^{\circ} \mathrm{C}$ a $37^{\circ} \mathrm{C}$ (MIGAKI et al., 1982; RANJAN et al., 2006).

Em tecidos ou em meios de cultura, as células de Prototheca apresentam-se desde esféricas a ovaladas, com citoplasma basofílico granular e pequeno núcleo central. O tamanho pode variar entre 1,3 e 13,4mm de diâmetro e 1,3 e 16,1 mm de comprimento. $\mathrm{O}$ agente possui parede celular hialina com aproximadamente 0,5mm de espessura (FONT \& HOOK, 1984; GREENE, 2006).

As espécies de Prototheca se reproduzem assexuadamente por septação interna irregular (endosporulação). O citoplasma da célula "mãe” se rompe e libera entre 2 e 20 células "filhas" (endosporos). Os endosporos se desenvolvem e reiniciam o ciclo das células de origem (HOLLINGSWORTH, 2000; LASSFLÖRL \& MAYR, 2007).

A morfologia da alga pode ser avaliada mediante colorações de Gram (VARGAS et al., 1998; GREENE, 2006), Giemsa, Panótico(RIBEIRO et al., 1998), hematoxilina - eosina (HE) [CHAO et al., 2002], além de outras colorações específicas para fungos, como o azul de algodão - “cotton blue”- (TYLER et al., 1980; VARGAS et al., 1998; RANJAN et al., 2006).

As espécies são diferenciadas com base nas características morfo-tintoriais e em testes de assimilação de açúcares e álcoois (MIGAKI et al., 1982). Adicionalmente, imunofluorescência (FONT \& HOOK, 1984), teste de sensibilidade ao clotrimazol (GREENE, 2006) e, recentemente, análise molecular utilizando a técnica da reação em cadeia pela polimerase (PCR) [ROESLER et al., 2003; TSUJI et al., 2006], são métodos alternativos no plano diagnóstico.
Epidemiologia

As algas do gênero Prototheca estão amplamente distribuídas em ambientes com alta umidade (solo, lama, esgoto, fezes). A partir desses locais o microrganismo contamina alimentos, água e fômites (GREENE, 2006; LASS-FLÖRL\& MAYR, 2007).

Há relatos do isolamento de Prototheca sp em pele, mucosas, urina e fezes do homem, de cães e de gatos (GREENE, 2006). Entretanto, o microrganismo é freqüentemente isolado do leite de vacas, secreções de vacas secas, ordenhadeira, fezes, cama dos animais, água e alimentos de propriedades rurais de exploração leiteira, nas quais a alga pode manter-se viável por semanas até meses no ambiente. O microrganismo pode ser isolado das fezes de suínos, porém, com menor freqüência (RANJAN et al., 2006).

Em cães, tem sido descrita a prototecose cutânea, decorrente provavelmente de inoculação traumática da alga ou contaminação de feridas. No entanto, a via oral parece representar a principal forma de infecção nesta espécie, visto que a colite hemorrágica é a manifestação clínica mais freqüente em cães (DILLBERGER et al., 1988; GREENE, 2006).

Em gatos, a prototecose é predominantemente cutânea, causada por $\boldsymbol{P}$. wickerhamii (FINNIE \& COLOE, 1981; COLOE \& ALLISON, 1982). Nesses casos, sugerese inoculação traumática da alga (DILLBERGER et al., 1988) secundária a arranhões em brigas por fêmeas, demarcação de território ou por fômites. Nas tabelas 1 a 5, apresentam-se dados clínico-epidemiológicos da prototecose em cães e gatos.

Entre os relatos de prototecose em cães e gatos, nota-se pouca preocupação com os dados epidemiológicos, principalmente, no tocante à origem dos animais e ao ambiente em que vivem. VAN KRUININGEN (1970), ao relatar prototecose entérica em cão, mencionou que o animal permaneceu confinado em canil por três meses antes de apresentar diarréia com sangue. FONT \& HOOK (1984) descreveram retinite por $\boldsymbol{P}$. wickerhamii, destacando a ausência de apetite depravado ou sintomas similares em cães contactantes. HOSAKA \& HOSAKA (2004) notificaram prototecose entérica em cão que se alimentava de restos de comida caseira. Em nenhum dos relatos supracitados os autores exploraram os fatores predisponentes da prototecose, em especial, o ambiente dos animais, considerado fundamental para o conhecimento epidemiológico da infecção e, conseqüentemente, para adoção de estratégias de controle e profilaxia. Em contraste, FARIAS et al. (2006), ao descreverem o primeiro caso de prototecose entérica no Brasil em cão, mostraram preocupação com os achados epidemiológicos, destacando a proveniência 
Tabela 1 - Dados clínico-epidemiológicos da prototecose em cães e gatos.

\begin{tabular}{|c|c|c|c|c|c|c|c|}
\hline & 1969 & 1969 & 1970 & 1973 & 1973 & 1975 & 1975 \\
\hline Espécie & can & can & can & can & can & can & can \\
\hline Idade & $9 a$ & 3a $6 \mathrm{~m}$ & 3a & $2 \mathrm{a}$ & 3a $6 \mathrm{~m}$ & $8 \mathrm{a} 6 \mathrm{~m}$ & $7 a$ \\
\hline Raça & Boxer & $\begin{array}{l}\text { Springer } \\
\text { spaniel }\end{array}$ & $\begin{array}{l}\text { Springer } \\
\text { spaniel }\end{array}$ & Schnauzer & Collie & Collie & NI \\
\hline Sexo & $\mathrm{F}$ & NI & M & $\mathrm{F}$ & M & $\mathrm{F}$ & M \\
\hline & cegueira, diarréia & $\begin{array}{c}\text { paralisia de } \\
\text { osteriores, fezes }\end{array}$ & & & & & \\
\hline Clínica & $\begin{array}{l}\text { com sangue, } \\
\text { poliúria, } \\
\text { polidipsia }\end{array}$ & $\begin{array}{l}\text { com estrias de } \\
\text { sangue, } \\
\text { polidipsia, } \\
\text { hematoquesia }\end{array}$ & $\begin{array}{l}\text { diarréia com } \\
\text { sangue }\end{array}$ & $\begin{array}{l}\text { otite, descarga } \\
\text { nasal }\end{array}$ & cegueira & $\begin{array}{l}\text { cegueira, diarréia } \\
\text { com sangue }\end{array}$ & infecção ocular \\
\hline $\begin{array}{l}\text { Tempo de } \\
\text { evolução }\end{array}$ & $10 \mathrm{~m}$ & $3 d$ & $3 m$ & $6 \mathrm{~m}$ & meses & $1 \mathrm{~m}$ & $\mathrm{NI}$ \\
\hline $\begin{array}{l}\text { Órgãos } \\
\text { acometidos }\end{array}$ & $\begin{array}{l}\text { coração, fígado, } \\
\text { rins, cérebro, } \\
\text { olhos }\end{array}$ & $\begin{array}{l}\text { reto, rins, } \\
\text { coração }\end{array}$ & $\begin{array}{l}\text { intestinos, } \\
\text { linfonodos } \\
\text { colônicos e } \\
\text { mesentéricos }\end{array}$ & $\begin{array}{c}\text { orelhas, pele, } \\
\text { linfonodos } \\
\text { cervicais, } \\
\text { pulmões }\end{array}$ & olhos & $\begin{array}{l}\text { intestinos, olhos, } \\
\text { pulmões, } \\
\text { linfonodos } \\
\text { mesentéricos, } \\
\text { rins, coração, } \\
\text { fígado, baço }\end{array}$ & olhos \\
\hline $\begin{array}{l}\text { Espécie de } \\
\text { Prototheca }\end{array}$ & $\begin{array}{c}\text { Prototheca } \\
\text { sp }\end{array}$ & $\begin{array}{c}\text { Prototheca } \\
\text { sp }\end{array}$ & $\begin{array}{c}\text { Prototheca } \\
\text { sp }\end{array}$ & $\begin{array}{c}\text { Prototheca } \\
\text { wickerhamii }\end{array}$ & Prototheca sp & $\begin{array}{c}\text { Prototheca } \\
\text { sp }\end{array}$ & Prototheca zopfii \\
\hline $\begin{array}{l}\text { Método de } \\
\text { diagnóstico }\end{array}$ & MO & MO & MO & $\mathrm{C}, \mathrm{AF}$ & MO & MO & MO \\
\hline País & EUA & Inglaterra & EUA & EUA & EUA & EUA & NI \\
\hline Referência & $\begin{array}{c}\text { VAN } \\
\text { KRUININGEN } \\
\text { et al., } 1969 .\end{array}$ & $\begin{array}{c}\text { POVEY } \\
\text { et al., } 1969 .\end{array}$ & $\begin{array}{c}\text { VAN } \\
\text { KRUININGEN, } \\
1970 .\end{array}$ & $\begin{array}{l}\text { SUDMAN } \\
\text { et al., } 1973 .\end{array}$ & $\begin{array}{r}\text { CARLTON \& } \\
\text { AUSTIN, } 1973 .\end{array}$ & $\begin{array}{c}\text { BUYUKMIHCI } \\
\text { et al., } 1975 .\end{array}$ & $\begin{array}{c}\text { MIGAKI } \\
\text { et al., } 1982 .\end{array}$ \\
\hline
\end{tabular}

a: ano/anos; can: canina; fel: felina; F: fêmea; M: macho; NI: não informado; m: mês/meses; d: dia/dias; MO: microscopia óptica; C: cultura; AF: anticorpos fluorescentes; EUA: Estados Unidos da América.

*: apenas citação.

de área rural do animal, fato que provavelmente contribuiu para o contato com o agente infeccioso nas fezes, na água e/ou no ambiente úmido.

Na ocorrência de prototecose no homem, têm sido descritos a procedência e o ambiente dos pacientes. CHAO et al. (2002) descreveram infecção em fazendeiras e laboratorista, ressaltando o componente ambiental na transmissão e o risco ocupacional da doença. A prototecose no homem também está associada a determinados grupos de risco, como pacientes submetidos à quimioterapia, co-infectados com doenças imunossupressivas - como a aids -, ou por contaminação de tubos endotraqueais e catéteres em ambientes hospitalares (THIELE \& BERGMANN, 2002; GREENE, 2006). MELÓN et al. (2007) relataram caso de peritonite por $\boldsymbol{P}$. wickerhamii em paciente dependente de diálise, portador de catéter peritoneal.

Aspectos patológicos

Nos cães, devido à grande variedade de tecidos acometidos, a prototecose é classificada como doença disseminada. A ação do microrganismo nos tecidos leva à formação de piogranulomas (GREENE, 2006), compostos por diferentes células, incluindo 
Tabela 2 - Dados clínico-epidemiológicos da prototecose em cães e gatos (continuação).

\begin{tabular}{|c|c|c|c|c|c|c|c|}
\hline & 1976 & $1976^{*}$ & 1977 & 1978 & 1980 & 1980 & $1980 *$ \\
\hline Espécie & can & fel & can & can & can & can & fel \\
\hline Idade & 1a $6 \mathrm{~m}$ & NI & $6 a$ & $2 \mathrm{a}$ & $4 a$ & За & NI \\
\hline Raça & Collie & NI & Doberman & $\begin{array}{l}\text { Hungarian } \\
\text { vitzla }\end{array}$ & SRD & SRD & NI \\
\hline Sexo & $\mathrm{F}$ & $\mathrm{NI}$ & $\mathrm{F}$ & $\mathrm{F}$ & F & $\mathrm{F}$ & $\mathrm{NI}$ \\
\hline Clínica & $\begin{array}{l}\text { diarréia com } \\
\text { sangue }\end{array}$ & NI & $\begin{array}{l}\text { cegueira, } \\
\text { paresia de } \\
\text { posterior }\end{array}$ & $\begin{array}{l}\text { cegueira, } \\
\text { diarréia com } \\
\text { sangue }\end{array}$ & $\begin{array}{c}\text { ataxia, } \\
\text { tetraparesia }\end{array}$ & $\begin{array}{l}\text { diarréia com } \\
\text { sangue }\end{array}$ & lesões de pele \\
\hline $\begin{array}{l}\text { Tempo de } \\
\text { evolução }\end{array}$ & $3 m$ & $\mathrm{NI}$ & $1 \mathrm{~m}$ & $9 \mathrm{~m}$ & $2 m$ & $2 \mathrm{~m}$ & $\mathrm{NI}$ \\
\hline $\begin{array}{c}\text { Órgãos } \\
\text { acometidos }\end{array}$ & $\begin{array}{l}\text { coração, cólon, } \\
\text { rins, fígado }\end{array}$ & $\mathrm{NI}$ & $\begin{array}{l}\text { olhos, rins, } \\
\text { fígado, } \\
\text { cérebro, baço, } \\
\text { pulmão }\end{array}$ & olhos, cólon & $\begin{array}{c}\text { cérebro, } \\
\text { medula } \\
\text { espinhal, } \\
\text { olhos, coração, } \\
\text { rins }\end{array}$ & rins, cólon & pele \\
\hline $\begin{array}{l}\text { Espécie de } \\
\text { Prototheca }\end{array}$ & $\begin{array}{c}\text { Prototheca } \\
\text { wickerhamii }\end{array}$ & NI & $\begin{array}{c}\text { Prototheca } \\
\text { zopfii }\end{array}$ & $\begin{array}{c}\text { Prototheca } \\
\text { wickerhamii }\end{array}$ & $\begin{array}{l}\text { P. zopfii, } P . \\
\text { wickerhamii }\end{array}$ & $\begin{array}{c}\text { Prototheca } \\
\text { zopfii }\end{array}$ & $\mathrm{NI}$ \\
\hline $\begin{array}{l}\text { Método de } \\
\text { diagnóstico }\end{array}$ & $\mathrm{AF}$ & NI & $\mathrm{AF}$ & $\mathrm{AF}, \mathrm{ME}$ & $\mathrm{AF}, \mathrm{C}, \mathrm{ME}$ & $\mathrm{AF}$ & NI \\
\hline País & EUA & EUA & África & EUA & EUA & EUA & EUA \\
\hline Referência & $\begin{array}{l}\text { HOLSCHER } \\
\text { et al., } 1976 .\end{array}$ & $\begin{array}{l}\text { KAPLAN } \\
\text { et al., } 1976 .\end{array}$ & $\begin{array}{c}\text { IMES } \\
\text { et al., } 1979 .\end{array}$ & $\begin{array}{c}\text { MIGAKI } \\
\text { et al., } 1982 .\end{array}$ & $\begin{array}{c}\text { TYLER } \\
\text { et al., } 1980 .\end{array}$ & $\begin{array}{l}\text { MIGAKI } \\
\text { et al, } 1982 .\end{array}$ & $\begin{array}{c}\text { FINNIE \& } \\
\text { COLOE, } 1981 .\end{array}$ \\
\hline
\end{tabular}

a: ano/anos; can: canina; fel: felina; F: fêmea; M: macho; NI: não informado; m: mês/meses; C: cultura; AF: anticorpos fluorescentes; ME: microscopia eletrônica; EUA: Estados Unidos da América.

*: apenas citação.

linfócitos, plasmócitos, macrófagos, neutrófilos, áreas de necrose central e destacado número de células de Prototheca (RALLIS et al., 2002). Nas lesões de evolução crônica, são observados macrófagos e células gigantes multinucleadas fagocitando a alga (HOLLINGSWORTH, 2000).

Nas infecções por via oral, acredita-se que a disseminação ocorra por via hemática e/ou linfática, após ingestão da alga, principalmente em hospedeiros imunocomprometidos (BLOGG \& SYKES, 1995; HOLLINGSWORTH, 2000; RALLIS et al., 2002).

Nos rins, as lesões apresentam-se maiores, chegando medir alguns centímetros, circundadas por anel hemorrágico. Também podem ser encontradas lesões lineares, que acometem as regiões cortical e medular renais (GREENE, 2006). O exame ocular de pacientes infectados revela descolamento de retina, desenvolvimento de uveíte, sinéquia (HOLLINGSWORTH, 2000) e catarata (FONT \& HOOK, 1984; BLOOG \& SYKES, 1995). No sistema nervoso central, podem ser observadas lesões disseminadas, caracterizadas por pequenos focos de necrose, circundados por infiltrado inflamatório (TYLER et al., 1980).

Nos animais de companhia, o trato intestinal representa o sistema mais freqüentemente acometido. Nas mucosas intestinais, as lesões variam entre extensas áreas avermelhadas e grandes regiões nodulares, hemorrágicas e ulceradas. Pequenos focos esbranquiçados podem ser observados em muscular e serosa(VAN KRUININGEM, 1970; GREENE, 2006).

$\mathrm{Na}$ prototecose cutânea, grandes 
Tabela 3 - Dados clínico-epidemiológicos da prototecose em cães e gatos (continuação).

\begin{tabular}{|c|c|c|c|c|c|c|c|}
\hline & 1981 & 1982 & 1982 & 1982 & $1984 *$ & 1984 & $1985 *$ \\
\hline Espécie & fel & can & can & fel & can & can & can \\
\hline Idade & $16 a$ & $5 a$ & $2 \mathrm{a}$ & $8 a$ & NI & $2 a$ & NI \\
\hline Raça & NI & Cocker & $\begin{array}{l}\text { Hungarian } \\
\text { vitzla }\end{array}$ & Short hair & NI & $\begin{array}{l}\text { Hungarian } \\
\text { vitzla }\end{array}$ & NI \\
\hline Sexo & M & NI & $\mathrm{F}$ & NI & NI & $\mathrm{F}$ & NI \\
\hline Clínica & nódulo cutâneo & $\begin{array}{c}\text { diarréia com } \\
\text { sangue, } \\
\text { vômitos, perda } \\
\text { de peso, ataxia, } \\
\text { anorexia, febre, } \\
\text { cegueira }\end{array}$ & $\begin{array}{l}\text { diarréia com } \\
\text { sangue, } \\
\text { descolamento } \\
\text { de retina }\end{array}$ & $\begin{array}{c}\text { nódulo em } \\
\text { coxim plantar }\end{array}$ & $\begin{array}{l}\text { rinite, cegueira, } \\
\text { disseminada }\end{array}$ & $\begin{array}{l}\text { diarréia com } \\
\text { sangue, } \\
\text { cegueira }\end{array}$ & disseminada \\
\hline $\begin{array}{l}\text { Tempo de } \\
\text { evolução }\end{array}$ & NI & $7 \mathrm{~m}$ & $9 m$ & NI & NI & $9 \mathrm{~m}$ & NI \\
\hline $\begin{array}{l}\text { Órgãos } \\
\text { acometidos }\end{array}$ & pele & rins & $\begin{array}{l}\text { olhos, } \\
\text { intestinos }\end{array}$ & pele & $\begin{array}{l}\text { olhos, aparelho } \\
\text { respiratório } \\
\text { superior }\end{array}$ & olhos, cólon & disseminada \\
\hline $\begin{array}{l}\text { Espécie de } \\
\text { Prototheca }\end{array}$ & $\begin{array}{c}\text { Prototheca } \\
\text { sp }\end{array}$ & $\begin{array}{c}\text { Prototheca } \\
\text { zopfii }\end{array}$ & $\begin{array}{c}\text { Prototheca } \\
\text { wickerhamii }\end{array}$ & $\begin{array}{l}\text { Prototheca } \\
\text { wickerhamii }\end{array}$ & NI & $\begin{array}{l}\text { Prototheca } \\
\text { wickerhamii }\end{array}$ & NI \\
\hline $\begin{array}{l}\text { Método de } \\
\text { diagnóstico }\end{array}$ & MO & $\mathrm{MO}, \mathrm{AF}$ & ME, MO, AF & $\mathrm{MO}, \mathrm{C}$ & NI & $\mathrm{MO}, \mathrm{AF}, \mathrm{ME}$ & NI \\
\hline País & EUA & EUA & EUA & Austrália & EUA & EUA & EUA \\
\hline Referência & $\begin{array}{c}\text { FINNIE \& } \\
\text { COLOE, } 1981 .\end{array}$ & $\begin{array}{c}\text { MIGAKI } \\
\text { et al., } 1982 .\end{array}$ & $\begin{array}{c}\text { BLOGG \& } \\
\text { SYKES, } 1995 .\end{array}$ & $\begin{array}{c}\text { COLOE \& } \\
\text { ALLISON, } \\
1982 .\end{array}$ & $\begin{array}{l}\text { BERROCAL et } \\
\text { al., } 1997 .\end{array}$ & $\begin{array}{c}\text { FONT \& } \\
\text { HOOK, } 1984 .\end{array}$ & $\begin{array}{c}\text { MOORE } \\
\text { et al., } 1985 .\end{array}$ \\
\hline
\end{tabular}

a: ano/anos; can: canina; fel: felina; F: fêmea; M: macho; NI: não informado; m: mês/meses; MO: microscopia óptica; C: cultura; AF: anticorpos fluorescentes; ME: microscopia eletrônica; EUA: Estados Unidos da América.

contingentes da alga são encontrados na derme, no subcutâneo e/ou na musculatura esquelética adjacente à lesão. A epiderme apresenta-se hiperqueratótica, inflamada e ulcerada (GREENE, 2006). As infecções cutâneas podem disseminar-se até a mucosa nasal, produzindo necrose, úlceras e hemorragias (TSUJI et al., 2006). Linfonodos regionais são comumente invadidos pelo microrganismo (GREENE, 2006).

Nos felinos predomina a forma localizada em derme e epiderme, porém, pode haver disseminação para tendões, nervos e vasos sangüíneos. Os granulomas são constituídos por macrófagos e células gigantes multinucleadas, além de neutrófilos e plasmócitos (GREENE, 2006).
Clínica

A prototecose canina apresenta-se sob diferentes manifestações clínicas. Diarréia com sangue intermitente é o sinal clínico mais freqüentemente relatado (HOLLINGSWORTH, 2000). Nos casos disseminados, $\boldsymbol{P}$. zopfii é a espécie mais comumente isolada (STENNER et al., 2007).

A prototecose cutânea é pouco freqüente nos cães, diferentemente do que ocorre nos gatos. As lesões de pele se caracterizam por nódulos, úlceras, crostas exsudativas no tronco, extremidades e superfícies mucosas (GINEI et al., 1997). Nestes casos há prevalência de $\boldsymbol{P}$. wickerhamii (GREENE, 2006).

TSUJI et al. (2006) descreveram caso raro de co-infecção em cão por $\boldsymbol{P}$. zopfii e $\boldsymbol{P}$. wickerhamii

Ciência Rural, v.38, n.6, set, 2008. 
Tabela 4 - Dados clínico-epidemiológicos da prototecose em cães e gatos (continuação).

\begin{tabular}{|c|c|c|c|c|c|c|c|}
\hline & 1988* & 1988 & 1988 & 1990 & 1995 & 1997 & 1997 \\
\hline Espécie & can & fel & fel & can & can & can & can \\
\hline Idade & NI & $10 \mathrm{a}$ & $7 a$ & NI & $5 a$ & $9 a$ & $4 a$ \\
\hline Raça & NI & Short hair & Short hair & Collie & Boxer & Poodle & Collie \\
\hline Sexo & NI & M & M & NI & $\mathrm{F}$ & $\mathrm{F}$ & M \\
\hline Clínica & dermatite & nódulo cutâneo & $\begin{array}{l}\text { nódulo nasal, } \\
\text { espirros }\end{array}$ & disseminada & $\begin{array}{l}\text { cegueira, } \\
\text { melena, } \\
\text { depressão }\end{array}$ & $\begin{array}{l}\text { torcicolo, otite, } \\
\text { nistagmo, } \\
\text { déficit } \\
\text { proprioceptivo }\end{array}$ & $\begin{array}{c}\text { dermatite } \\
\text { escrotal, } \\
\text { fissuras nos } \\
\text { coxins, nódulos } \\
\text { cutâneos, } \\
\text { espirros }\end{array}$ \\
\hline $\begin{array}{l}\text { Tempo de } \\
\text { evolução }\end{array}$ & NI & $6 \mathrm{~m}$ & $6 \mathrm{~m}$ & NI & $5 d$ & NI & $2 \mathrm{~m}$ \\
\hline $\begin{array}{c}\text { Órgãos } \\
\text { acometidos }\end{array}$ & pele & pele & pele & disseminada & $\begin{array}{c}\text { estômago, } \\
\text { intestinos, } \\
\text { coração, olhos }\end{array}$ & $\begin{array}{l}\text { rins, coração, } \\
\text { fígado }\end{array}$ & pele \\
\hline $\begin{array}{l}\text { Espécie de } \\
\text { Prototheca }\end{array}$ & NI & $\begin{array}{l}\text { Prototheca } \\
\text { wickerhamii }\end{array}$ & $\begin{array}{c}\text { Prototheca } \\
\text { wickerhamii }\end{array}$ & NI & Prototheca sp & $\begin{array}{c}\text { Prototheca } \\
\text { sp }\end{array}$ & $\begin{array}{c}\text { Prototheca } \\
\text { wickerhamii }\end{array}$ \\
\hline $\begin{array}{l}\text { Método de } \\
\text { diagnóstico }\end{array}$ & NI & MO, C & MO, C & NI & MO & MO, ME & MO, C \\
\hline País & Inglaterra & EUA & EUA & Austrália & EUA & Costa Rica & Espanha \\
\hline Referência & $\begin{array}{l}\text { MACARTNEY } \\
\text { et al., } 1988 .\end{array}$ & $\begin{array}{l}\text { DILLBERGER } \\
\text { et al., } 1988 .\end{array}$ & $\begin{array}{l}\text { DILLBERGER } \\
\text { et al., } 1988 .\end{array}$ & $\begin{array}{c}\text { BLOGG \& } \\
\text { SYKES, } 1995 .\end{array}$ & $\begin{array}{c}\text { BLOGG \& } \\
\text { SYKES, } 1995 .\end{array}$ & $\begin{array}{l}\text { BERROCAL } \\
\text { et al., } 1997 .\end{array}$ & $\begin{array}{c}\text { GINEI } \\
\text { et al., } 1997 .\end{array}$ \\
\hline
\end{tabular}

a: ano/anos; can: canina; fel: felina; F: fêmea; M: macho; NI: não informado; m: mês/meses; d: dia/dias; MO: microscopia óptica; C: cultura; ME: microscopia eletrônica; EUA: Estados Unidos da América.

*: apenas citação.

em apresentação disseminada, sendo que o animal apresentava febre, distensão abdominal, perda de peso, erosões no espelho nasal, esplenomegalia e linfoadenomegalia.

Os animais com acometimento ocular podem apresentar cegueira repentina (FONT \& HOOK, 1984; BLOGG \& SYKES, 1995). Comumente há acometimento dos dois olhos, porém, a sintomatologia pode ser assimétrica (HOLLINGSWORTH, 2000).

As fêmeas da raça Collie são aparentemente mais susceptíveis em face do grande número de relatos, porém, parece não haver predisposição etária (GREENE, 2006). Em investigação da prototecose em 17 cães entre 1988 e 2005 na Austrália, STENNER et al. (2007) também encontraram maior freqüência de infecção em fêmeas. No entanto, sete eram da raça Boxer e seis mestiços da raça.
Há relatos de prototecose cutânea em gatos, causada exclusivamente por $\boldsymbol{P}$. wickerhamii. Esses animais geralmente se apresentam em bom estado geral (FINNIE \& COLOE, 1981). As lesões se caracterizam por nódulos firmes, pouco doloridos e grandes. Os locais mais acometidos são focinho, pina e face (GREENE, 2006). Animais com acometimento nasal freqüentemente apresentam episódios de espirros (DILLBERGER et al., 1988). Diferentes autores referem que a lambedura excessiva das lesões poderia causar dermatite secundária (COLOE \& ALLISON, 1982).

\section{Diagnóstico}

A maioria dos casos relatados de prototecose em animais de companhia não apresenta informações epidemiológicas. A despeito desta 
Tabela 5 - Dados clínico-epidemiológicos da prototecose em cães e gatos (continuação).

\begin{tabular}{|c|c|c|c|c|}
\hline & 2002 & 2004 & 2006 & 2006 \\
\hline Espécie & can & can & can & can \\
\hline Idade & 3a $6 \mathrm{~m}$ & $10 \mathrm{a}$ & $4 a$ & $8 a$ \\
\hline Raça & Pastor alemão & Mongrel & Maltês & SRD \\
\hline Sexo & M & NI & $\mathrm{F}$ & M \\
\hline Clínica & $\begin{array}{l}\text { diarréia com sangue, } \\
\text { tenesmo, vômitos, febre }\end{array}$ & $\begin{array}{l}\text { hematoquesia, hemorragia } \\
\text { anal, tenesmo }\end{array}$ & $\begin{array}{l}\text { febre, distensão } \\
\text { abdominal, perda de peso, } \\
\text { ulceração nasal }\end{array}$ & $\begin{array}{l}\text { diarréia com sangue, } \\
\text { inapetência, perda de } \\
\text { peso, tenesmo, } \\
\text { desidratação }\end{array}$ \\
\hline Tempo de evolução & $1 \mathrm{~m}$ & $1 \mathrm{~m}$ & NI & $1 \mathrm{~m}$ \\
\hline Òrgãos acometidos & $\begin{array}{c}\text { linfonodos mesentéricos, } \\
\text { intestinos }\end{array}$ & $\begin{array}{l}\text { intestinos, linfonodos } \\
\text { mesentéricos, coração, } \\
\text { rins, estômago }\end{array}$ & $\begin{array}{l}\text { pulmão, baço, fígado, } \\
\text { esôfago, olhos, língua, } \\
\text { coxins }\end{array}$ & intestinos \\
\hline Espécie de Prototheca & Prototheca sp & Prototheca zopfii & Prototheca wickerhamii & Prototheca zopfii \\
\hline Método de diagnóstico & MO & MO, C & MO, C, PCR & MO, ME, C \\
\hline País & Grécia & Japão & Japão & Brasil \\
\hline Referência & RALLIS et al., 2002. & $\begin{array}{l}\text { HOSAKA \& HOSAKA, } \\
2004 .\end{array}$ & TSUJI et al., 2006. & FARIAS et al., 2006. \\
\hline
\end{tabular}

a: ano/anos; can: canina; fel: felina; F: fêmea; M: macho; NI: não informado; m: mês/meses; MO: microscopia óptica; C: cultura; ME: microscopia eletrônica; PCR: reação em cadeia pela polimerase.

escassez de dados, o contato de cães suspeitos com ambiente rural, o histórico de brigas constantes entre gatos, ou mesmo a co-habitação com animais de produção são informações relevantes ao se aventar o diagnóstico da prototecose.

Clinicamente o principal sinal em cães é a ocorrência de diarréia crônica, porém, a enfermidade pode evoluir para sinais oculares e/ou neurológicos. Em gatos, predominam as lesões tegumentares, em região de face e plano nasal, mesmo em animais em bom estado geral.

Não há achados hematológicos característicos no hemograma e no leucograma dos animais (FELDMAN et al., 2000). Na bioquímica sérica podem ser observadas leves alterações em enzimas hepáticas. Nos animais com comprometimento sistêmico, pode haver falência renal aguda (BLOGG \& SYKES, 1995). O exame do líquor em animais com sinais neurológicos revela pleiocitose (maior que 100céls. $\mathrm{ml}^{-1}$ ) e aumento de proteína (maior que $100 \mathrm{mg} \mathrm{dl}^{-1}$ ) [GREENE, 2006].

O diagnóstico da prototecose em animais de companhia pode ser realizado pelo exame citológico.
Exames histológicos também são conclusivos, possibilitando a visualização de Prototheca sp em qualquer estágio de desenvolvimento (GREENE, 2006).

Diferentes métodos tintoriais já foram descritos no diagnóstico da prototecose mostrando a amplitude de colorações que podem ser utilizadas na identificação morfo-tintorial da alga. Na coloração de Gram, Prototheca sp se apresenta de tonalidade azulada (QUINN et al.,1994). A hematoxilina-eosina mostra microrganismos com parede refringente e de coloração eosinofílica (TYLER et al., 1980), enquanto que o citoplasma apresenta-se pouco corado, com septações que tornam as estruturas semelhantes às mórulas (CHAO et al., 2002; ZAITZ et al., 2006a).

Microrganismos em diferentes fases de reprodução, característicos do gênero Prototheca, são observados à microscopia eletrônica de varredura ou transmissão. Entretanto, é um método de uso restrito, utilizado principalmente em pesquisas (BERROCAL et al., 1997; VARGAS et al., 1998; COSTA et al., 2004), em virtude do custo elevado e do reduzido número de 
Tabela 6 - Protocolos terapêuticos para prototecose em cães.

\begin{tabular}{|c|c|c|c|c|c|c|c|c|}
\hline Agente & $\begin{array}{c}\text { Principais } \\
\text { sinais }\end{array}$ & Tratamento & Dose & Intervalo & Duração & Eficácia & País & Referência \\
\hline \multirow{3}{*}{ P. zopfii } & \multirow{3}{*}{$\begin{array}{c}\text { colite } \\
\text { hemorrágica }\end{array}$} & fluconazol & $5 \mathrm{mg} \mathrm{kg}{ }^{-1}$ & 2x/dia & 90 dias & não & \multirow{3}{*}{ Brasil } & \multirow{3}{*}{$\begin{array}{l}\text { FARIAS et al., } \\
2006\end{array}$} \\
\hline & & $\begin{array}{l}\text { nistatina } \\
\text { (inicial) }\end{array}$ & 500.000UI & 3x/dia & 7 dias & \multirow[t]{2}{*}{ sim } & & \\
\hline & & nistatina & 100.000UI & 3x/dia & remissão & & & \\
\hline \multirow{2}{*}{ P. zopfii } & \multirow{2}{*}{$\begin{array}{c}\text { colite } \\
\text { hemorrágica }\end{array}$} & sulfasalazina & $10 \mathrm{mg} \mathrm{kg}^{-1}$ & 2x/dia & 25 dias & \multirow{2}{*}{ não } & \multirow{2}{*}{ Japão } & \multirow{2}{*}{$\begin{array}{c}\text { HOSAKA \& } \\
\text { HOSAKA, } \\
2004\end{array}$} \\
\hline & & metronidazol & $20 \mathrm{mg} \mathrm{kg}^{-1}$ & 2x/dia & 59 dias & & & \\
\hline \multirow[t]{2}{*}{ Prototheca sp } & \multirow[t]{2}{*}{$\begin{array}{c}\text { colite } \\
\text { hemorrágica }\end{array}$} & cetoconazol & $30 \mathrm{mg} \mathrm{kg}^{-1}$ & 2x/dia & 30 dias & \multirow[t]{2}{*}{ não } & Grécia & $\begin{array}{c}\text { RALLIS et al., } \\
2002\end{array}$ \\
\hline & & cetoconazol & $15 \mathrm{mg} \mathrm{kg}^{-1}$ & 1x/dia & 6 meses & & & \multirow{4}{*}{$\begin{array}{c}\text { GINEI et al., } \\
1997\end{array}$} \\
\hline \multirow[t]{3}{*}{ P. wickerhamii } & \multirow[t]{3}{*}{$\begin{array}{l}\text { nódulos } \\
\text { cutâneos }\end{array}$} & $\begin{array}{c}+ \\
\text { tiabendazol }\end{array}$ & $10 \mathrm{mg} \mathrm{kg}^{-1}$ & 3/3 dias & 4 semanas & \multirow[t]{3}{*}{$\operatorname{sim}$} & \multirow[t]{3}{*}{ Espanha } & \\
\hline & & P. acnes & vide bula & vide bula & vide bula & & & \\
\hline & & gentamicina & $2 \mathrm{mg} \mathrm{kg}^{-1}$ & 3x/dia & & & & \\
\hline \multirow{4}{*}{$\begin{array}{l}\text { P. zopfii } \\
+ \\
\text { P. wickerhamii }\end{array}$} & \multirow{4}{*}{$\begin{array}{c}\text { alterações } \\
\text { neurológicas }\end{array}$} & + & & & & \multirow{4}{*}{ não } & \multirow{4}{*}{ EUA } & \multirow{4}{*}{$\begin{array}{c}\text { TYLER et al., } \\
1980\end{array}$} \\
\hline & & ampicilina & $22 \mathrm{mg} \mathrm{kg}^{-1}$ & 3x/dia & 7 dias & & & \\
\hline & & + & & & & & & \\
\hline & & dexametasona & $2 \mathrm{mg} \mathrm{kg}^{-1}$ & - & & & & \\
\hline
\end{tabular}

P. acnes: Propionebacterium acnes; UI: unidades internacionais; mg/kg: miligramas por quilo; EUA: Estados Unidos da América.

laboratórios que disponibilizam a técnica na rotina diagnóstica.

Até o momento, o isolamento e a identificação microbiológica são os métodos mais acurados para a confirmação diagnóstica (QUINN et al., 1994). Rotineiramente utiliza-se o ágar Sabouraud, sem ciclohexamida, adicionado de antimicrobianos (cloranfenicol, gentamicina), incubado entre 25 e $37^{\circ} \mathrm{C}$, durante dois a sete dias, em condições de aerobiose. As colônias se apresentam mucóides e com a coloração variando do transparente ao branco (SHAHAN \& PORE, 1991). Nos meios de ágar sangue bovino ou ovino (5\%), a $37^{\circ} \mathrm{C}$, em aerobiose, dois a sete dias, as colônias apresentam-se mucóides e em tons de cinza-amarelado (QUINN et al., 1994). O crescimento é diminuto ou ausente em ágar Mac Conkey (RIBEIRO et al., 1998). Alternativamente, o uso de discos impregnados com 50mg de clotrimazol é um método simples, indicado para diferenciar $\boldsymbol{P}$. wickerhamii de $\boldsymbol{P}$. zopfii, uma vez que a primeira espécie é sensível a este antimicrobiano (LASSFLÖRL \& MAYR, 2007). Contudo, para diferenciação confiável entre as diversas espécies do microrganismo recomenda-se o uso de testes bioquímicos de assimilação de álcoois e açúcares (TSUJI et al., 2006).

Técnicas imunológicas utilizando-se anticorpos específicos, como a imunofluorescência - tanto em cortes histológicos quanto em lâminas também são indicadas no diagnóstico (MIGAKI et al., 1982; THIELE \& BERGMANN, 2002). O teste imunoenzimático de ELISA (Enzyme Linked Immunosorbent Assay) foi desenvolvido para o diagnóstico da prototecose na detecção de imunoglobulinas específicas (IgA e IgG1), no soro de vacas com mastite crônica, mostrando alta sensibilidade e especificidade (RANJAN et al., 2006). Entretanto, não estão disponíveis estudos que comprovem seu uso no sorodiagnóstico de animais de companhia.

Em anos recentes, as técnicas de diagnóstico molecular, como a PCR e o sequenciamento genético, foram descritas na identificação da prototecose bovina, visando a caracterização e a diferenciação de espécies e biotipos de Prototheca (MÖLLER et al., 2006; ROESLER et al., 2006). TSUJI et al. (2006) empregaram diagnóstico molecular em caso de infecção sistêmica por $\boldsymbol{P}$. wikerhamii em cão.

Nos cães, os casos de prototecose cutânea devem ser diferenciados principalmente de fungos como Blastomyces sp, Cryptococcus sp, Candida sp, Histoplasma capsulatum, Coccidioides immitis, Geotrichum candidum e Pneumocystis sp, além de protozoários como Caryospora sp (BLOGG \& SYKES, 1995; GINEI et al., 1997; MURRAY et al., 2007). 
Nos distúrbios oculares, deve-se avaliar a presença de outras causas, como coriorretinite, uveíte, descolamento de retina por neoplasias e hipertensão (BLOGG \& SYKES, 1995).

Nos casos de diarréia com sangue, o diferencial deve ser realizado principalmente para verminoses (Ancylostoma sp, Trichuris sp, Giardia sp) (VAN KRUININGEN, 1970; RALLIS et al., 2002), além da parvovirose e coronavirose em cães jovens (GREENE, 2006).

Nos gatos, a forma cutânea de prototecose requer diferencial com Coccidioids immitis, Sporothrix schenckii e Cryptococcus neoformans (COLOE \& ALLISON, 1982).

\section{Tratamento}

Nos casos de prototecose cutânea, obtémse sucesso com excisão cirúrgica do nódulo aliada ao uso de antimicrobianos sistêmicos (anfotericina B, tetraciclinas), combinados ou não com itraconazol (GREENE, 2006), cetoconazol ou fluconazol. Estas drogas também são utilizadas no tratamento de casos sistêmicos. Entretanto, o sucesso da terapia da prototecose em animais de companhia é controverso entre os autores (TYLER et al., 1980; FONT \& HOOK, 1984; DILLBERGER et al., 1988; GINEI et al., 1997; HOLLINGSWORTH, 2000; RALLIS et al., 2002; HOSAKA \& HOSAKA, 2004; GREENE, 2006; STENNER et al., 2007). De acordo com LASS-FLÖRL \& MAYR (2007), a ação variável de drogas antifúngicas frente às algas do gênero Prototheca pode ser explicada pela presença de ergosterol, substância presente primariamente na parede celular de fungos na parede celular do microrganismo. Diferentes protocolos terapêuticos utilizados na prototecose em cães e sua eficiência estão resumidos na tabela 6 .

Experimentalmente o uso de imunoestimulantes, como Propionibacterium acnes, sugere que estas drogas possam auxiliar no tratamento da prototecose (GINEI et al., 1997).

\section{Prevenção e controle}

A distribuição ubíqua do organismo dificulta a preconização de medidas específicas de controle e profilaxia. Diferente das fêmeas bovinas, nas quais a doença pode ocorrer sob a forma de surtos desencadeados por problemas de manejo (COSTA et al., 2004), nos animais de companhia a prototecose é reconhecida como doença individual.

A ação limitada das drogas e a inexistência de medicamentos específicos contra Prototheca sp reforçam a importância de instituir medidas de controle e prevenção para reduzir a exposição ao agente infeccioso. Separar animais doentes, manter o ambiente seco, limpo e exposto à luz solar, usar luvas no manuseio de animais doentes, além de remover materiais orgânicos, são medidas higiênico-sanitárias simples e adequadas que podem diminuir as infecções por microrganismos ambientais.

Prototecose em outras espécies domésticas

A infecção mamária é a principal manifestação clínica da prototecose em animais de produção. Em vacas o microrganismo é eliminado intermitentemente no leite (RANJAN et al., 2006). A alga é termo-resistente, refratária às condições de tempo/temperatura dos processos de pasteurização rápida e lenta, constituindo o leite e seus derivados em vias de transmissão para o homem (MELVILLE et al., 1999).

O gênero Prototheca mantém-se viável no interior de macrófagos e neutrófilos dos alvéolos mamários e também no interstício, podendo disseminarse para linfonodos supramamários (RANJAN et al., 2006). A resposta inflamatória é usualmente severa podendo gerar perda funcional da glândula mamária (COSTA et al., 2004).

O controle da enfermidade fundamenta-se na secagem dos quartos acometidos, no descarte das fêmeas e no cuidado em não adquirir animais de propriedades endêmicas. Não existem evidências da infecção cruzada entre espécies animais (RIBEIRO et al., 1998). Porém, o consumo de leite contaminado pelos bezerros pode levar à ocorrência de gastroenterite (COSTA et al., 2004).

Até o momento a doença parece não apresentar importância epidemiológica em outros ruminantes domésticos (búfalos, ovinos e caprinos) e em eqüinos. A alga pode ser isolada de fezes de suínos, embora pareça não apresentar patogenicidade para a espécie.

Saúde pública

No homem a infecção por Prototheca é observada na pele e no tecido subcutâneo. Também há relatos de acometimento de mucosas, articulações e formas generalizadas (THIELE \& BERGMANN, 2002; VAN BEZOOIJEN \& NEWLING, 2002).

A prototecose cutânea se caracteriza por nódulos eritematosos, úlceras e/ou placas (CHAO et al., 2002). Como nos gatos, $\boldsymbol{P}$. wickerhamii é a espécie mais freqüentemente isolada da pele dos pacientes (ZAITZ et al., 2006a). À semelhança com os cães, em casos sistêmicos, há prevalência de $\boldsymbol{P}$. zopfii (VAN BEZOOIJEN \& NEWLING, 2002). No entanto, ZHAO et al. (2003) descreveram prototecose cutânea por $\boldsymbol{P}$. 
zopfii em menina chinesa sem sintomas sistêmicos, porém, com lesões em pescoço e face.

Em indivíduos imunocompetentes, o microrganismo parece apresentar baixa virulência. No entanto, assume importância em pacientes imunossuprimidos, especialmente portadores do vírus da imunodeficiência humana, de neoplasias e de transplantados (LASS-FLÖRL \& MAYR, 2007).

Nos relatos de prototecose humana, são enfatizadas as relações com atividade rural e de jardinagem, comprovando a importância do ambiente para a infecção. MARCANO \& FEO (1981), na Venezuela, relataram prototecose por $\boldsymbol{P}$. zopfii nas unhas das mãos de paciente saudável. No Brasil, ZAITZ et al. (2006b) relataram o primeiro caso de onicoprototecose por $\boldsymbol{P}$. wickerhamii em mulher hígida. O contato freqüente com água também é descrito como fator predisponente para o desenvolvimento de lesões nas unhas (GALÁN et al., 1997).

COSTA et al. (1998) descreveram o isolamento de $\boldsymbol{P}$. zopfii a partir das fezes de proprietário rural, após consumo de queijo fresco produzido com leite de vacas com mastite por $\boldsymbol{P}$. zopfii. O paciente apresentou distúrbios gastrintestinais dias depois, comprovando que o microrganismo pode causar infecção em indivíduos saudáveis que consumam alimentos contaminados.

\section{CONCLUSÕES}

A prototecose é considerada doença rara em animais de companhia e zoonose veiculada por leite e derivados. Em cães o principal sintoma clínico é a colite hemorrágica, enquanto que em gatos predominam as infecções cutâneas. A terapia é prolongada e de sucesso variável. Estudos moleculares recentes têm procurado avaliar os biótipos da alga a fim de auxiliar na compreensão dos mecanismos de transmissão e, conseqüentemente, na adoção de medidas de controle. O risco de infecções laborais e o potencial zoonótico do microrganismo apontam o médico veterinário como importante agente de saúde na prevenção e no controle de infecções por algas do gênero Prototheca.

\section{REFERÊNCIAS}

BERROCAL, A. et al. Prototecosis sistémica en un canino. Descripción patológica de un caso. Arch Med Vet, v.29, n.2, p.1-9, 1997.

BLOGG, J.; SYKES, J.E. Sudden blindness associated with protothecosis in a dog. Aust Vet J, v.72, n.4, p.147-149, 1995.
BUYUKMIHCI, N. et al. Protothecosis with ocular involvement in a dog. J Am Vet Med Assoc, v.167, p.158-161, 1975.

CARLTON, W.W.; AUSTIN, L. Ocular protothecosis in a dog. Vet Pathol, v.10, p.274-280, 1973.

CHAO, S.C. et al. Cutaneous protothecosis: report of five cases. Brit J Dermatol, v.146, p.688-693, 2002.

COLOE, P.J.; ALlisOn, J.F. Protothecosis in a cat. J Am Vet Med Assoc, v.180, p.78-79, 1982.

COSTA, E.O. et al. Relato de um caso de consumo de queijo fresco contaminado com Prototheca spp. NAPGAMA, n.1, p.9-10, 1998.

COSTA, E.O. et al. Diagnosis of clinical bovine mastitis by fine needle aspiration followed by staining and scanning electron microscopy in a Prototheca zopfii outbreak. Mycopathol, v.158, p.81-85, 2004

DILLBERGER, J.E. et al. Protothecosis in two cats. J Am Vet Med Assoc, v.192, p.1557-1559, 1988.

FARIAS, M.R. et al. Colite crônica em cão, secundária a prototecose: primeiro relato no Brasil. In: CONGRESSO BRASILEIRO DA ANCLIVEPA, 27., 2006, Vitória. Anais... Vitória: Associação nacional de Clínicos Veterinários de Pequenos Animais, 2006. p.60.

FELDMAN, B.F. et al. Schalm's veterinary hematology. 5.ed. Canada: Lippincott Williams \& Wilkins, 2000. 1344p.

FINNIE, J.W.; COLOE, P.J. Cutaneous protothecosis in a cat. Aust Vet J, v.57, p.307-308, 1981.

FONT, R.L.; HOOK, S.R. Metastatic protothecal retinits in a dog. Electron microscopic observations. Vet Pathol, v.21, p.61-66, 1984.

GALÁN, F. et al. Onychoprotothecosis due to Prototheca wickerhamii. Mycopathol, v.137, p.75-77, 1997.

GINEI, P.J. et al. Cutaneous protothecosis in a dog. Vet Rec, v.140, p.651-653, 1997.

GREENE, C.E. Infectious diseases of the dog and cat. 3.ed. Canada: Saunders/Elsevier, 2006. 1387p.

HOLLINGSWORTH, S.R. Canine protothecosis. Vet Clin North Am Small Anim Pract, v.30, n.5, p.1091-1101, 2000.

HOLSCHER, M.A. et al. Disseminated canine protothecosis: a case report. J Am Anim Hosp Assoc, v.12, p.49-52, 1976.

HOSAKA, S.; HOSAKA, M. A case report of canine protothecosis. J Vet Med Sci, n.66, v.5, p.593-597, 2004.

IMES, G.D. et al. Disseminated protothecosis in a dog. Onderstepoort J Vet Res, v.44, p.1-6, 1977.

KAPLAN, W. et al. Protothecosis in a cat: first recorded case. Sabouraudia, n.14, p.281-286, 1976.

LASS-FLÖRL, C.; MAYR, A. Human protothecosis. Clin Microbiol Rev, v.20, n.2, p.230-242, 2007.

Ciência Rural, v.38, n.6, set, 2008. 
MACARTNEY, L. et al. Cutaneous protothecosis in a dog: first confirmed case in Britain. Vet Rec, v.123, p.494-496, 1988.

MARCANO, C.; FEO, M. Prototheca zopfii residente de uña. Mycopathol, v.75, p.89-92, 1981.

MELÓN, C.P. et al. Peritonitis por Prototheca wickerhamii en pacientes en diálisis peritoneal. Nefrol, v.27, n.1, p.81-82, 2007.

MELVILLE, P.A. et al. Evaluation of the susceptibility of Prototheca zopfii to milk pasteurization. Mycopathol, v.146, p.79-82, 1999.

MIGAKI, G. et al. Canine protothecosis: review of the literature and report of an additional case. J Am Vet Med Assoc, v.181, p.794-797, 1982

MÖLLER, A. et al. Prototheca zopfii genotype 2. The causative agent of bovine protothecal mastitis. Vet Microbiol, v.39, p.1-7, 2006

MOORE, F.M. et al. Unsuccessful treatment of disseminated protothecosis in a dog. J Am Vet Med Assoc, v.186, p.705708, 1985

MURRAY, P.R. et al. Manual of clinical microbiology. 9.ed. Washington: ASM, 2007. 2256p.

POVEY, R.C. et al. A case of protothecosis in a dog. Pathol Vet, n.6, p.396-402, 1969

QUINN. P.J. et al. Clinical veterinary microbiology. London: Wolfe, 1994. 648p.

RALLIS, T.S. et al. Protothecal colitis in a german sheperd dog. Aust Vet J, v.80, n.7, p.406-408, 2002.

RANJAN, R. et al. Bovine protothecal mastitis: a review. Perspect Agric Vet Sci Nutr Nat Res, v.1, n.17, p.1-7, 2006.

RIBEIRO, M.G. et al. Mastite bovina por Prototheca zopfii. Relato de caso e revisão de literatura. Biológico, v.60, n.1, p.1-7, 1998.

ROESLER, U. et al. Emended phenotypic characterization of Prototheca zopfii: a proposal for three biotypes and standards for their identification. Int J Syst Evol Microbiol, v.53, p.1195-1199, 2003.
ROESLER, U. et al. Diversity within the current algal species Prototheca zopfii: a proposal for two Prototheca zopfii genotypes and description of a novel species, Prototheca blaschkeae sp. nov. Int J Syst Evol Microbiol, v.56, p.1-7, 2006.

SHAHAN, T.A.; PORE, R.S. In vitro susceptibility of Prototheca spp. to gentamicin. Antimicrob Ag Chemoter, v.35, n.11, p.2434-2435, 1991.

STENNER, V.J. et al. Protothecosis in 17 Australian dogs and review of the canine literature. Med Mycol, v.45, n.3, p.249266, 2007.

SUDMAN, M.S. et al. P rimary mucocutaneous protothecosis in a dog. J Am Vet Med Assoc, v.163, p.1372-1374, 1973.

THIELE, D.; BERGMANN, A. Protothecosis in human medicine. Int J Hyg Environ Health, v.204, p.297-302, 2002

TSUJI, H. et al. An isolate of Prototheca wickerhamii from systemic canine protothecosis. Vet Microbiol, v.118, n.3-4, p.305-311, 2006.

TYLER, E. et al. Disseminated protothecosis with central nervous system involvement in a dog. J Am Vet Med Assoc, v.176, p. 987-993, 1980.

VAN BEZOOIJEN, B.P.J.; NEWLING, D.W.W. Protothecosis of the urinary tract. J Urol, v.167, p.252, 2002.

VAN KRUiningen, H.J. et al. Protothecosis in a dog. Path Vet, v.6, p.348-354, 1969.

VAN KRUININGEN, H.J. Protothecal enterocolitis in a dog. J Am Vet Med Assoc, v.157, p.56-63, 1970

VARGAS, A.C. et al. Isolation of Prototheca zopfii from a case of bovine mastitis in Brazil. Mycopathol, v.142, p.135-137, 1998.

ZAITZ, C. et al. Cutaneous protothecosis: report a third brazilian case. Int J Dermatol, v.45, p.124-126, 2006a.

ZAITZ, C. et al. Onychoprotothecosis: report of the first case in Brazil. Int J Dermatol, v.45, p.1071-1073, 2006b.

ZHAO, J. et al. Protothecosis successfully treated with amikacin combined with tetracyclines. Mycoses, v.47, p.156-158, 2003. 